Supporting Information for Org. Lett. (o1047749p)

\title{
Selective Organocatalytic Oxygenation of Hydrocarbons by Dioxygen Using Anthraquinones and $N$-Hydroxyphthalimide
}

\author{
Guanyu Yang, ${ }^{\dagger, \star}$ Qiaohong Zhang, ${ }^{\dagger}$ Hong Miao, ${ }^{\dagger}$ Xinli Tong, ${ }^{\dagger}$ and Jie $\mathrm{Xu}^{*}{ }^{* \dagger}$ \\ ${ }^{\dagger}$ State Key Laboratory of Catalysis, Dalian Institute of Chemical Physics, Graduate School of the \\ Chinese Academy of Sciences, Chinese Academy of Sciences, 457 Zhongshan Road, Dalian, 116023, \\ P. R. China \\ ${ }^{\ddagger}$ Department of Chemistry, Zhengzhou University, 75 Daxue Road, Zhengzhou, 450052, P. R. \\ China
}

General Information. All experiments were carried out in a closed Teflon-lined 70-ml stainless steel autoclave. GC-MS was performed on Agilent 6890N GC / 5973 MS detector. ${ }^{1} \mathrm{H}$ NMR spectrum was recorded on a Bruker DRX-400FT using CDCl3 as the solvent with TMS as an internal reference. Column chromatography was performed using silica gel (particle size 75-150 $\mu \mathrm{m}$ ). The commercial anthraquinones were purified prior to use by recrystallization according to the methods collected in Beilstein CrossFire. $N$-Hydroxyphthalimide, fluorene, acenaphthene, and adamantane were recrystallized by absolute ethanol before use. Cyclohexene, tetralin, indane, and ethylbenzene were purified prior to use following the guidelines of Perrin et al. ${ }^{1}$ Cyclohexane, toluene, and acetonitrile are purchased from Tianjin kermel Chemical

(1) Perrin, D. D.; Armarego, W. L. F.; Perrin, D, R. Purification of Laboratory Chemicals; 2nd ed., Pergamon Press, Oxford, 1980. 
Regent Development Center, directly used without further purification.

Typical procedure for oxygenation. In a typical experiment, the hydrocarbon ( 5.0 mmol ), anthraquinone ( $1.25 \mathrm{~mol} \%$ ), NHPI ( $5 \mathrm{~mol} \%$ ), and acetonitrile (10 ml) were added into a Teflon-lined 70-ml stainless steel autoclave. After closing the autoclave, the air inside was replaced with $\mathrm{O}_{2}$ for three times. Under stirring, preheated to $80{ }^{\circ} \mathrm{C}$, and then charged $\mathrm{O}_{2}$ to $0.30 \mathrm{MPa}$ to start the reaction. During the reaction, if the pressure of $\mathrm{O}_{2}$ decreased to $0.25 \mathrm{MPa}$, charged $\mathrm{O}_{2}$ to $0.30 \mathrm{MPa}$ again. Stop the reaction at the predetermined time.

The reaction data were obtained by two methods as follows:

Method A: The reaction mixture that had been cooled to room temperature was transferred carefully to a $50-\mathrm{mL}$ volumetric flask, The autoclave was washed with acetone for five times ( $5 \mathrm{ml}$ each time) and the solutions were also transferred to the volumetric flask. Added definite amount of the internal standard and excess of $\mathrm{Ph}_{3} \mathrm{P}$, and then filled to the mark with acetone. After let it stand for 1h, measured by GC.

Method B: The reaction mixture that had been cooled to room temperature was transferred carefully to a 50-mL volumetric flask, The autoclave was washed with acetone for five times ( $5 \mathrm{ml}$ each time) and the solutions were also transferred to the volumetric flask. Then fill to the mark with acetone. $5 \mathrm{~mL}$ of the solution was used for GC analysis according to Method A. Another 15-20 mL of the solution was used for isolation of the corresponding oxygenated products. The isolation procedure was conducted as follow: After the solvents was removed under reduced pressure, the residue was purified by silica-gel column chromatography, eluted initially with 
hexanes to remove the unreacted hydrocarbon substrate, and then eluted with EtOAc / hexanes ( $\mathrm{v}: \mathrm{v}=1: 10)$ to afford the corresponding oxygenated product.

The isolation procedure for fluorenone: After the oxygenation of fluorene was finished, the mixture that had been cooled to room temperature was transferred to a flask. The autoclave was washed with ethanol for five times ( $2 \mathrm{ml}$ in each time) and the solutions were also transferred the flask. $10 \mathrm{~mL}$ aqueous solution of $2.0 \mathrm{~g}$ semicarbazide hydrochloride and $2.5 \mathrm{~g}$ sodium acetate was added. After stiring at room temperature for $5 \mathrm{~h}$ under reduced presusure at room temperature, and then staying in refrigerator for $5 \mathrm{~h}$, the resulting solid ( catalysts and formed semicarbazone of fluorenone ) was collected by filtration. The solid mixture was washed with cyclohexane for five times ( $10 \mathrm{ml}$ each time) to remove fluorene, and then transferred into a two-neck flask, $3 \mathrm{~mL}$ concentration sulfuric acid, $15 \mathrm{~mL}$ water and $15 \mathrm{~mL}$ ethanol were added, and refluxed at stirring for $2 \mathrm{~h}$. The revived fluorenone was distilled out by steam distillation. After staying in refrigerator for $5 \mathrm{~h}$, The distillate was filtered to give fluorenone as a yellow solid. The GC results showed that the purity of fluorenone was over $99 \%$.

All products are known, and were confirmed by GC-MS analysis, ${ }^{1} \mathrm{H}$ NMR spectroscopy, and the comparison of their GC retention time with those of authentic samples.

9-Fluorenone: Yellow powder. ${ }^{1} \mathrm{H} \mathrm{NMR}\left(\mathrm{CDCl}_{3}, \mathrm{TMS}\right): \delta 7.25-7.28(\mathrm{~m}, 2 \mathrm{H}$, aromatic 
hydrogen), 7.43-7.49 (m, 4H, aromatic hydrogens), 7.62-7.64 (d, 2H, aromatic hydrogen).

1-Tetralone: liquid, ${ }^{1} \mathrm{H}$ NMR $\left(\mathrm{CDCl}_{3}\right.$, TMS): $\delta$ 2.09-2.16 (m, 2H, $\left.\mathrm{CH}_{2}\right), 2.63-2.66(\mathrm{t}$, $\left.2 \mathrm{H}, \mathrm{CH}_{2}\right), 2.94-2.97\left(\mathrm{t}, 2 \mathrm{H}, \mathrm{CH}_{2}\right), 7.23-7.31(\mathrm{~m}, 2 \mathrm{H}$, aromatic hydrogens ), 7.43-7.47 (m, $1 \mathrm{H}$, aromatic hydrogen), 8.01-8.03 ( $\mathrm{m}, 1 \mathrm{H}$, aromatic hydrogen). 1-Acenaphthenone: white solid, ${ }^{1} \mathrm{H}$ NMR $\left(\mathrm{CDCl}_{3}, \mathrm{TMS}\right): \delta 3.81\left(\mathrm{~s}, 2 \mathrm{H}, \mathrm{CH}_{2}\right)$, 7.44-7.46 $(\mathrm{d}, 1 \mathrm{H}$, aromatic hydrogens $)$, 7.57-7.61 (t, 1H, aromatic hydrogen), 7.68-7.72 (t, 1H, aromatic hydrogen), 7.80-7.82 (d, 1H, aromatic hydrogen), 7.94-7.96 (d, 1H, aromatic hydrogen), 8.07-8.09 (d, 1H, aromatic hydrogen).

Acetophenone: colorless liquid, ${ }^{1} \mathrm{H}$ NMR $\left(\mathrm{CDCl}_{3}, \mathrm{TMS}\right): \delta 2.58\left(\mathrm{~s}, 3 \mathrm{H}, \mathrm{CH}_{3}\right)$, 7.42-7.46 (m, 2H, aromatic hydrogens), 7.52-7.54 (m, 1H, aromatic hydrogen), 7.93-7.95 (m, 2H, aromatic hydrogens).

1-Indanone: liquid, ${ }^{1} \mathrm{H} \mathrm{NMR}\left(\mathrm{CDCl}_{3}, \mathrm{TMS}\right): \delta 2.67-2.70\left(\mathrm{t}, 2 \mathrm{H}, \mathrm{CH}_{2}\right), 3.12-3.16(\mathrm{t}, 2 \mathrm{H}$, $\left.\mathrm{CH}_{2}\right), 7.34-7.38(\mathrm{t}, 1 \mathrm{H}$, aromatic hydrogen), 7.46-7.51 (m, 1H, aromatic hydrogen), 7.56-7.59 (t, 1H, aromatic hydrogen), 7.75-7.77(d 1H, aromatic hydrogen).

GC Measurement. Gas chromatography measurements were conducted using a Agilent model 4890D gas chromatograph with a flame ionization detector. A PEG-20M capillary column $(50 \mathrm{~m} \times 0.32 \mathrm{~mm} \times 0.4 \mathrm{um})$ and a OV-1701 capillary column $(30 \mathrm{~m} \times 0.25 \mathrm{~mm} \times 0.3 \mathrm{um})$ were used to separate products for the reaction with different substrates, respectively. Quantitation of components was performed by the internal standard method. 
General GC conditions: detector: $240{ }^{\circ} \mathrm{C}$; injection: $250{ }^{\circ} \mathrm{C}$; carrier gas: nitrogen; carrier gas rate: $1.0 \mathrm{~mL} / \mathrm{min}$.

Fluorene and their corresponding oxygenated products were detected with OV-1701 capillary column and the following column temperature program: hold at $180^{\circ}$ for 3 minutes and then increase at $20^{\circ}$ per minute to $220^{\circ}$. 1,2-Dichlorobenzene was used as an internal standard.

Cyclohexene and their corresponding oxygenated products were detected with OV-1701 capillary column and the following column temperature program: hold at $60^{\circ}$ for 3 minutes and then increase at $20^{\circ}$ per minute to $220^{\circ}$. Toluene was used as an internal standard.

Tetralin and their corresponding oxygenated products were detected with PEG-20M capillary column and the following column temperature program: hold at $120^{\circ}$ for 3 minutes and then increase at $20^{\circ}$ per minute to $220^{\circ} .1,2$-Dichlorobenzene was used as an internal standard.

Indane and their corresponding oxygenated products were detected with OV-1701 capillary column and the following column temperature program: hold at $120^{\circ}$ for 2 minutes and then increase at $20^{\circ}$ per minute to $220^{\circ} .1,2$-Dichlorobenzene was used as an internal standard.

Acenaphthene and their corresponding oxygenated products were detected with OV-1701 capillary column and the following column temperature program: hold at $120^{\circ}$ for 2 minutes and then increase at $20^{\circ}$ per minute to $220^{\circ}$. 1,2-Dichlorobenzene 
was used as an internal standard.

Cyclohexane and their corresponding oxygenated products were detected with OV-1701 capillary column and the following column temperature program: hold at $80^{\circ}$ for 3 minutes and then increase at $20^{\circ}$ per minute to $220^{\circ}$. Toluene was used as an internal standard.

Toluene and their corresponding oxygenated products were detected with PEG-20M capillary column and the following column temperature program: hold at $80^{\circ}$ for 5 minutes and then increase at $30^{\circ}$ per minute to $220^{\circ}$. 1,2,4,5-Tetramethylbenzene was used as an internal standard.

Ethylbenzene and their corresponding oxygenated products were detected with PEG-20M capillary column and the following column temperature program: hold at $100^{\circ}$ for 5 minutes and then increase at $10^{\circ}$ per minute to $220^{\circ}$. 1,2,4,5-Tetramethylbenzene was used as an internal standard.

Adamantane and their corresponding oxygenated products were detected with OV-1701 capillary column and the following column temperature program: hold at $80^{\circ}$ for 3 minutes and then increase at $30^{\circ}$ per minute to $220^{\circ}$. 1,2-Dichlorobenzene was used as an internal standard. 